Ambient Science, 2014: Vol. 1(1); 29-37

DOI:10.21276/ambi.2014.01.1.ra03

ambient

RESEARCH ARTICLE

\title{
Human-Wildlife Conflicts in Arid Areas of Western India: Strategies for Mutual Co-Existence
}

Study Area: Gujrat, India

Coordinates: variable

\author{
Darshana Patel $^{1,2}$ - Nishith Dharaiya ${ }^{1 *}$ \\ 'Department of Life Sciences, HNG University, \\ Patan, Gujarat 384265 \\ ${ }^{2}$ Presently at Smt. S. R. Patel Engineering College, \\ Dabhi (Dist. Mehsana) Gujarat, India
}

Key words: Sloth bear, Herbivores, Carnivores, Human-wildlife conflicts

\section{Abstract}

The study has been carried out in the North Gujarat region of Gujarat state, Western India which represents unique habitats from arid regions to dry deciduous forests with annual rainfall ranging from 25-125 cms. Humanwildlife conflicts are intensifying owing to increase in human population and destruction of wildlife habitats. In the present study we characterized and classified the conflicts, identified zones with acute conflicts and evaluated the economic loss to the local villagers due to such humanwildlife conflicts. Sampling methods mainly included village surveys for interviewing locals who are affected by wildlife damage. The information was overlaid on the existing digital land use data to identify landscape characteristics associated with wildlife occupancy in the region. The result depicts that $80 \%$ of total damage in seasonal crop is caused by wild ungulates. Wild animals like Blue bull, Wild boar and Porcupine are reported as a chief crop raider. The Leopard is the only big cat occurring in the region reported to cause human injury and livestock predation. Sloth bear attacks on human are very common in some part of the study area. Conflicts are more severe around unprotected forests while high intensity of conflicts was recorded on the fringes of the forests. Less compensation and delayed process of compensation by the government makes the local community more hostile towards the presence of wildlife in thearea.

*Corresponding Author: nadharaiya@gmail.com 


\section{Introduction}

Day by day the conflict between wildlife and human is extending owing to increasing human population, loss of natural habitats for wildlife and gradual increase in their population due to successful conservation efforts of Indian government after the implication of Wildlife Protection Act, 1972. Conflicts are most acute when the species involved is critically imperiled while its presence in an area poses a significant threat to human welfare (Dharaiya, 2001). Human- Wildlife conflicts in the general terms occur due to several reasons; human death or injury is one of them known as direct loss to human and become the chief reason of conflicts. Despite this the economic loss due to wildlife such as livestock predation and crop damage are the other prime situations resulting conflicts. Many research studies have been promoted by various authorities to resolve such conflicts and to develop the strategies by which the conflicts can be minimized. Even the forest officials and field staff are also actively involved in such activities. Regular increase in Human- Wildlife conflicts are probably due to rapid increase in various anthropogenic practices that reduces wildlife habitats, forest cover and obliterates the wildlife corridors in many areas of the state and country. In Gujarat the human injuries and death are very common due to attack by large cats like Asiatic lion (Panthera leo persica) and leopard (P. pardus) respectively. Attack by sloth bear (Melursus ursinus) is also reported increasing since last many years due to reduction in the sloth bear habitat especially in North Gujarat.

Apart from these direct encounters and indirect conflicts leading to economic loss to humans are also rising at very high rate. The indirect conflicts are mainly crop damage by ungulate, rodents and other animals as well as the predation of livestock by some large and medium sized carnivores. In such cases it is very necessary to understand the economic conditions of local people in order to find solutions to the conflicts (Ikeda, 2004). Systematic assessment and evaluation of man-animal conflicts in the different parts of the region will provide the baseline information through which some remedial measures can be suggested. The proposed research is aimed to assess and evaluate both direct and indirect conflicts between human and wildlife in the North Gujarat region and to suggest possible remedies for their coexistence.

The region of North Gujarat is composed of very low forest cover, vast arid land and is highly dominated by agricultural and pastoral activities (Gajera \& Dharaiya, 2011). The economy of this region is largely depends upon the agriculture and milk production hence the livestock and crop loss means a lot to the local peopleand make them hostiles towards wildlife. This situation demands an urgent solutions and strategy by which man and wildlife can coexist in the area. This can be achieved by evaluating rate of

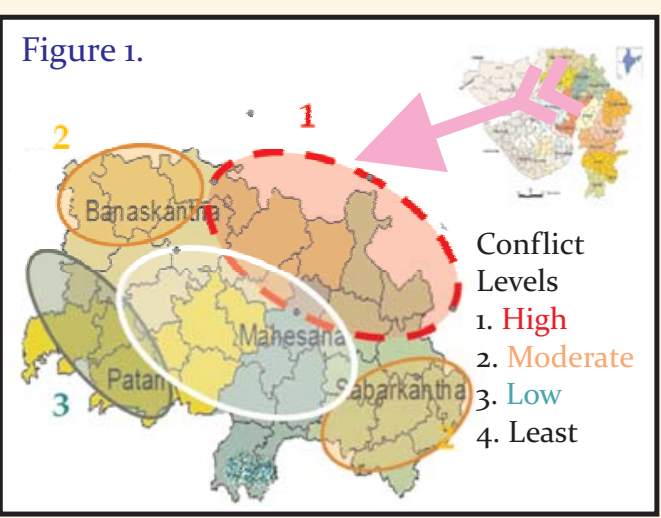

Identified conflict zones in the study area based on secondary data 
conflicts in different parts of the region such as forested area, arid areas, urban and sub urban areas. The present study has been carried out in two of the districts of North Gujarat region viz. Mehsana and Patan as these two districts of falls under arid to semi-arid areas of the region.

\section{Materials and Methods:}

The North Gujarat region is composed of four districts viz. Banaskantha, Mehsana, Patan and Sabarkantha (Fig.- 1). Geographically the region falls in biogeographic zone 4- The Semi-Arid and Into Biotic Province $4 \mathrm{~B}$ of the Gujarat Rajvada. It can be further classif ied into sub biotic province $4 \mathrm{~B} 3$-hilly area of Sabarkantha and Banaskantha and ${ }_{4} \mathrm{~B}_{4}$ - the arid lands of Mehsana and Patan District (Singh 2002). It is a land of pastoral and agricultural activities with very few forest patches around. The mountains of Aravalis are terminated in this region playing an important role as a barrier against the progressing desert; parts of western Aravalis in Sabarkantha and Banaskantha have good patches of dry deciduous and thorny forest which shows moderating effect on the climate of North Gujarat.

Human population is now separating into the wilderness areas; there are more than 350 small and big forested villages found in the vicinity of the forest, out of which 25 villages are located on the border of Jassor Wildlife Sanctuary and about 90 villages are located in and around Balaram- Ambaji Wildlife Sanctuary (Dharaiya, 2008). These villages are mainly occupied by the tribal communities, according to the census; the total human population in the studyarea is more than 800,000 .

Although the forest cover is very low in the region, there are some patches with good forest cover and harboring signif icant population of wild animals including, sloth bear, leopard, blue bull (Boselaphus tragocamelus), striped hyena (Hyaena hyaena), wolf (Canis lupus), jackal (Canis aurius), porcupine (Hystrix indica), wild boar (Sus scrofa), etc. These animals often found moving outside the forest area in search of food or water and they confronted human, that generally result in injury or death of either man or wildlife. The animals like blue bull, porcupine, sloth bear, wild ass and wild boar are destroying the standing crop very frequently in the area and causes voluminous loss to farmers. Among these blue bull is now become a problem wildlife and pest to the standing crop almost throughout the state.

The main local communities of the people residing are Rajput Garasia, Bhil Garasia among the tribal in Sabarkantha and Banaskantha, whereas the people working in the salt pans of saline lands of Patan are called Agaria. The villagers mainly keep cow, buffalo, goat, sheep, camel, horse and domestic ass as the livestock. These livestock population is utmost important being a main source of livelihood through the sale of milk and milk products.

Study has been started from May 2009 with secondary data collection from forest off ices of concern sub districts (Taluka) of the region; the information includes range maps of the district, forest cover, presence of wildlife, cases recorded of human-wildlife conflicts, records of compensation claimed by villagers, wildlife death, human injury/death cases etc. Concurrently extensive field work spanned over a period of twelve months from May 2009 to April 2010, which was started by interviewing respondents from villages using preformatted and field tested questionnaires. The questionnaire includes the information about, human 
injury/death by wildlife, Economic loss caused through crop damage and peoples' perception who have not confronted with wildlife.

People were also inquired whether they claimed for compensation after the wildlife attack, in such cases details of compensation were also collected.

The flow and details of questions themselves were adjusted to improve the communicative quality of the questionnaires. Study has been conducted randomly as around $75 \%$ of villages from each sub district. The respondents in the study area were also categorized by their castes, categories and community such as upper castes, other backward class (OBC), Scheduled caste (SC) and scheduled tribe (ST). Respondents above 18 years of age were interviewed for all the questionnaires. One respondent for each interview was treated as a representative of the village. In addition the GPS locations of surveyed villages, sites of attacks and crop damage sites were recorded for special analysis. This information is overlaid on the forest cover map through Q-GIS ${ }^{\circledast}$ and conflict sites and situations were studied.

\section{Results and Discussion:}

Overall, 142 species (149 species including unconf irmed sightings) were recorded Overall, 142 The study area (Mehsana and Patan) falls in arid- semi arid region of Gujarat, is mainly conquered as saline desert (Little Rann of Kachchh), agricultural and pastoral land, social forestry, Gram Vatikas and rest part of forest cover. As the area having low and unpredictable rainfall and inadequate forest cover to sustain the life, HumanWildlife interactions become unavoidable concern. Table 1 depicts the generalized picture of area studied. Using secondary information different zones prone to human-wildlife conflicts were identified, and village survey was conducted in these zones. Based on these survey human-wildlife conflicts were overlaid on the district forest cover map (Fig.- 4).

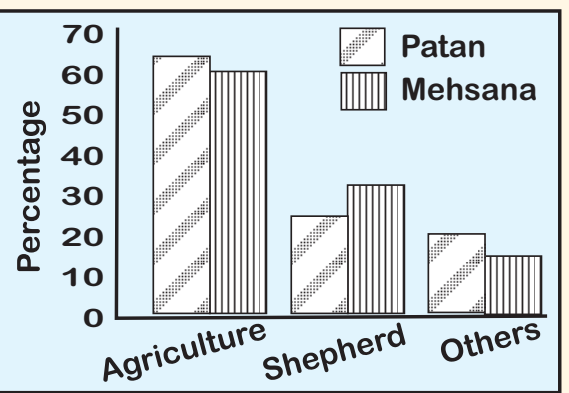

Figure 2. Occupation status of the respondents in the study area

Table 1. \# Taluka and Villages surveyed in two districts

\begin{tabular}{|lllll|}
\hline No. & District & Total Taluka & \# Taluka Surveyed & \# Village surveyed \\
\hline $\mathbf{1}$ & Mehsana & 9 & 5 & $\mathbf{2 0 3}$ \\
\hline $\mathbf{2}$ & Patan & 7 & 4 & $\mathbf{2}$ \\
\hline
\end{tabular}

We have also classif ied the conflict types and nature of conflicts in different area. Table 2 shows around $75 \%$ of the cases recorded in the study area were of indirect conflicts such as crop damage $(71.45 \%)$ and livestock depredation $(2.80 \%)$ while around $25 \%$ cases were recorded as direct conflicts including human injury (26.04\%) and death of wild or human (0.15\%) cases were around $25 \%$. Leopard is the only big cat in the study area and occurs only in Mehsana district which is mainly reported for livestock depredation. While widely distributed wild herbivores like blue bull and wild boar were reported in throughout the study area and 
Table 2. \% Cases recorded of Human-Wildlife conflicts based on village survey

\begin{tabular}{|r|l|r|}
\hline No. & Type of conflicts & \multicolumn{2}{|c|}{$\%$ Cases recorded } \\
\hline & & $(\mathrm{n}=1993)^{*}$ \\
\hline & Direct Conflict & $(26.19)$ \\
\hline 1 & Human Injury & 26.04 \\
\hline 3 & Wildlife Mortality & 0.15 \\
\hline & Indirect Conflicts & $(74.25)$ \\
\hline 1 & Crop Damage & 71.45 \\
\hline 2 & Livestock Depredation & 2.80 \\
\hline 3 & Infrastructural Damage & o \\
\hline 4 & Habitat Encroachment & o \\
\hline
\end{tabular}

( ${ }^{*}$ Few cases have recorded for both kinds of conflicts and were not repeated in sample size)

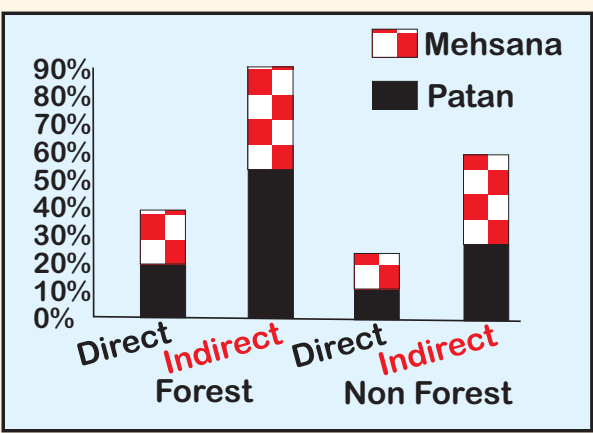

Figure 3. \% cases recorded in forest and non forested areas

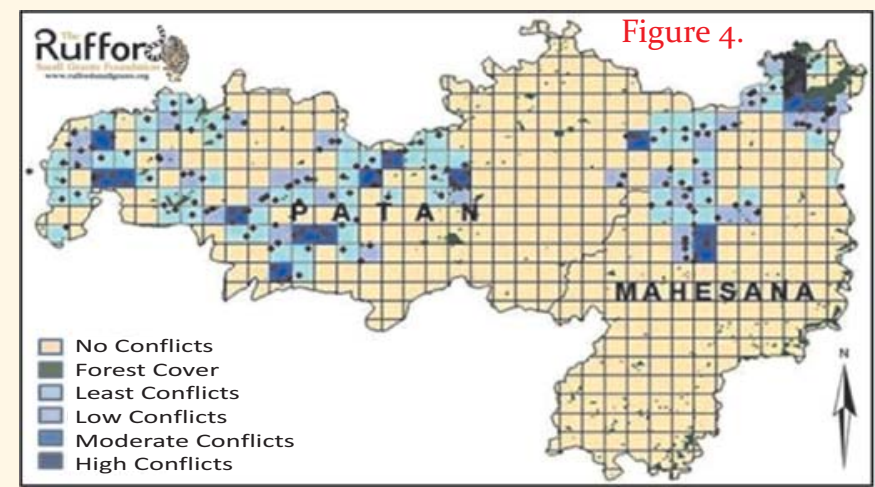

Intensity of human- wildlife conflicts in forest and non forest areas (Fig.-2). damaging the standing crops. Infrastructural damage has not been reported in the study area; however there is a scheme of compensation for such damage by the state government.

Total numbers of respondent interviewed were 1673 . Out of the them $75 \%$ were male and $25 \%$ were female. The average age of respondents was 50.00 $( \pm 1.89)$ years. Of the total respondents $42.75 \%$ were illiterate, $31.03 \%$ had studied up to primary level education, $16.15 \%$ had done higher secondary school and $10.05 \%$ had completed their graduation. This reflects that almost $50 \%$ of the respondents are well literate in the area. Further, $59 \%$ of the respondents were farmers by their occupation, whereas $26.41 \%$ were shepherds engaged in pastoral activities. The rest of respondents were involved in other occupations like service, business and labor work

Figure 4 shows the spatial analysis of the humanwildlife conflict locations, which clearly depicts that the areas near the forest boundaries, unprotected and reserved forests as well as near roads have comparatively higher rate of conflicts than that of the other intermediating villages (Fig.-3). Moreover majority of the direct conflicts were occurred in the unprotected forest areas of Mehsana reflecting presence of wildlife as well as human activities in such forest areas.

The main animal found responsible for small injuries and attack on human is Wild boar. Wild boar attacks were recorded at the rate of about 3-4 attacks per month (Fig.5), while livestock depredation, major human injury and death in the region 

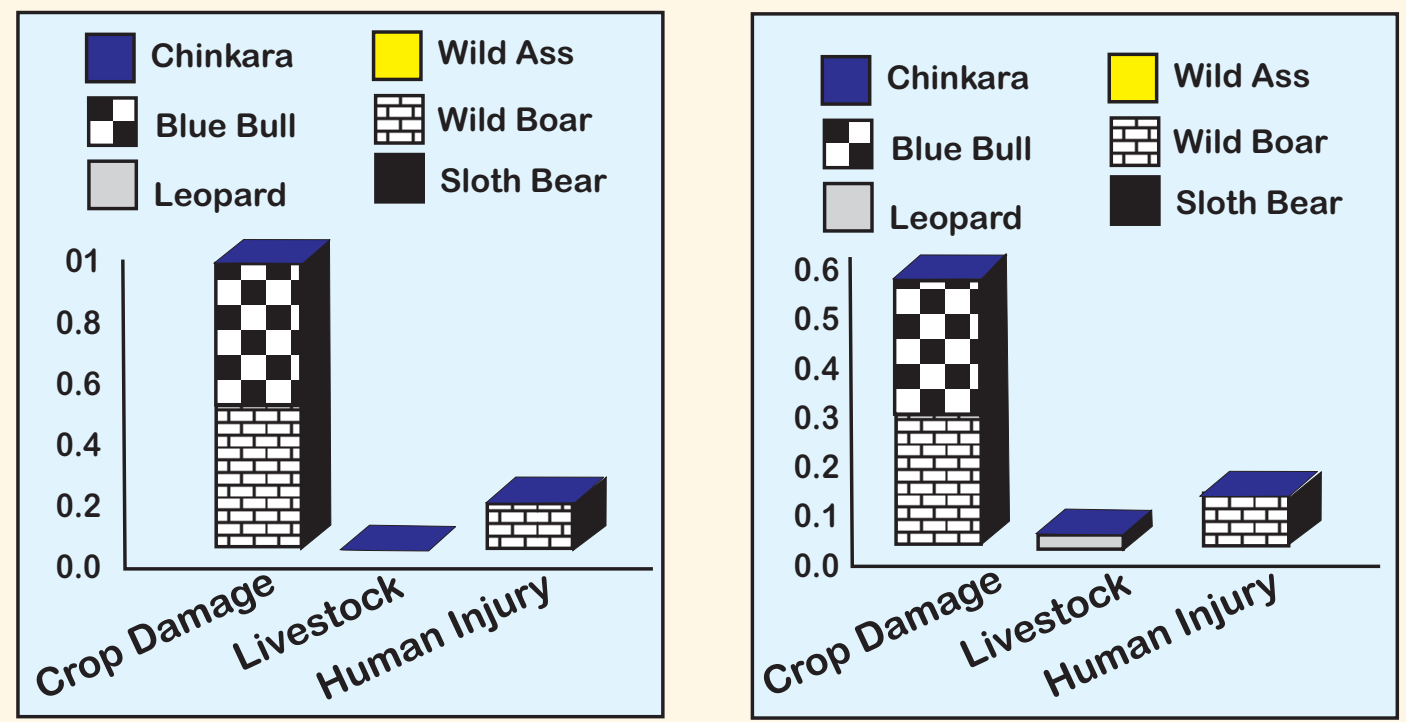

Figure 5. Various causes of conflict and wildlife involved in Patan (a) and Mehsana (b)

are mainly caused by Leopard and Sloth bear respectively (Fig.-5a). Forest patches along Mehsana are referred as potential bear habitats but its fragmentation and uncontrolled human activities has resulted in bear attacks on humans (Dharaiya \& Ratnayeke 2009). It is also observed that bears too visit neighboring villages mainly for search of water and food and causes severe human injuries; this situation has made locals more hostile towards wildlife and sometime leading to killing of wildlife (Dharaiya \& Ratnayeke, 2009).

Sloth bear, Leopard and Wild boar are major responsible wildlife for direct conflicts where as other large herbivores are reported for crop damage causing economic loss. Blue bull and wild boar found comparatively higher in both the districts. As these two animals are herbivore and less natural habitat and resources always comes in a picture as nuisance of agriculture damage. The continuous conflicts make these animals more aggressive which in turn result in attacks leading to human injury or death and seldom an animal too become a victim. The rate of human injury/ death due to wild animal attack in both the districts is shown in figure $5 \mathrm{~b}$. This reveals that the conflicts are more acute in Mehsana as both bear and leopards are occurring in this area, while livestock depredation and human injury by Leopard were recorded higher due to the connectivity of landscapes with forest areas of western Aravalli. Wild Ass is endemic to north Gujarat and Kachchh which was almost vulnerable before a decade; however currently the number of Wild Ass is increasing due to successful conservation efforts and increasing local awareness. This condition leads stress on the agricultural lands as fewer natural resources available in the region.

During the study it has been found that all the parts of every crop are eaten by these wild animals in all the seasons. Blue bull shows a preference on uppermost fruit parts (MAL), Wild boar use mainly root parts and Wild Ass consumes almost the entire crop as a food, which itself attest the signif icant agricultural loss in the region due to wild animals. This is accompanied by 
Table 3. Comparison of market price of livestock with compensation paid by the forest department

\begin{tabular}{|llll|}
\hline No & Livestock Type & $\begin{array}{l}\text { Approximate } \\
\text { Market Price } \\
\text { (INR) }\end{array}$ & $\begin{array}{l}\text { \% Compensation } \\
\text { paid by Forest } \\
\text { Department }\end{array}$ \\
\hline 1 & Buffalo(Milking) & 45000 & 12.22 \\
\hline 2 & Buffalo & 25000 & 16.00 \\
\hline 3 & Cow (Milking) & 10000 & 30.00 \\
\hline 4 & Cow & 20000 & 22.50 \\
\hline 5 & Sheep and Goat & 6000 & 16.66 INR: Indian Rupees \\
\hline
\end{tabular}

the climatic peculiarities of this region like unpredictable rainfall, frequent draught, disease, etc. The study shows that different factors responsible for agricultural loss, crop damage due to wildlife is the major concern; as it can be managed through suitable wildlife control techniques than the other are natural happening which are unpredictable and much complicated to manage. An average of $25 \%$ agricultural damage is only due to wildlife which leads to economic loss to respondents about Rs. 2-500o per Biga of land during sawing season, Rs. 20-4000o during growing and harvesting periods, which totals the average loss of Rs. 20-300oo per farmer per year in a Biga of land.

Table 3 reveals the \% compensation paid by forest department for livestock killed and their current market price. Figures show that respondents receive only $19 \%$ amount of the market rate as compensation for livestock depredation. Moreover processing time of this compensation is around 9 to 10 months. This may be the reason that more than $75 \%$ of local people do not tolerate the presence of wildlife in the area.

The study also illustrates the awareness about the compensation schemes by the government for economic loss due to wildlife. $66 \%$ people are aware with the scheme whereas $11 \%$ of people were claimed for compensation against the livestock depredation.

In response to the question; "What is their opinion about the Wild animals living in their Surroundings?" the responses of the respondents were polarized as they give religious importance to Blue bull as they are locally called as Nilgai. On the other hand, blue bulls are reported as one of the most destructive animal to standing crop in the entire state (Singh, 2002).

Human injury, death, crop damage and livestock predation are the root cause that make the people hostile towards wildlife and persuades the conflicts. It is the need of the time to find out some solutions to minimize the conflicts between man and wildlife and to promote wildlife conservation through peoples' participation. It is also need of the recent time in this region to develop some techniques and suggest some strategies for human- wildlife coexistence; through evaluation and assessment of such conflicts by systematic and scientif ic research.

As stated earlier, the economy of the people and the entire region is chiefly depends on the agricultural and livestock products; the people may never ready to bare such losses due to presence of wild animal in the area. In such circumstances it is very urgent to suggest new techniques to minimize conflicts and avoid direct confrontations of people and wildlife in the region. 


\section{Possible steps for mitigating conflicts:}

Some amount of conflict is unavoidable when large carnivores inhabit human dominated landscapes (Namgial et al., 2006). To minimize the impact of conflict reactive and proactive measures need to be taken (Madhusudan \& Mishra, 2003). Compensating for livestock depredation is one of the most common mitigation measures as this process is a complex and longtime delay between the claim and the reimbursements. Compensations are paid only at the end of the financial year in many parts of India (Mishra, 1997); however in Gujarat the compensation are paid at any time but, the process for applying and approving is more complex. As a result the local people have found to refuse for applying. It also involves considerable documentation work some time photographic evidences of the event. These complex and bureaucratic processes discourage people from availing these schemes. For the large carnivore like leopards to survive in a human dominated landscape there is a need of eff icient management practices to be employed, both on the part of wildlife managers as well as the local people (Linnell et al., 2001). Wildlife conservation in human dominated area is more a policy issue than the scientific and ecological one. Thus systematic scientif ic research can help in formulating better and efficient management policy that may aid in reducing conflicts. Primm \& Clark (1996) have also suggested developing the management plans using scientif ic research in carnivore conservation.

Awareness is the most effective practice for both wildlife conservation and sustainable development. The present study recommends to initiate awareness campaigns in the area do develop community based conservation practices. People should also encourage applying for compensation by transforming the scheme into people friendly process and providing them a prescribed format for such application. Increasing number in wildlife population and their infiltration in the villages can be altered by expanding forest habitats through reforestation and declaring carnivore dominated landscapes as protected area. The overall study depicts that human-wildlife conflicts are acute where the land use patterns are changing this can be overcome by altering habitat alteration. Peoples' attitude can also be changed by awareness and increasing the rate of compensation against their livestock depredation.

Acknowledgements

One of the authors (D.Patel)is grateful to the Chief Conservator of Forests, Gujarat Forest Research Institute, Gandhinagar and the Rufford's Foundation, London for financial assistance. Thanks are also due to the Deputy Conservators of Forests and all field staff of the forest divisions of North Gujarat region for their support in the field work and providing timely information. Head, department of life sciences, HNG University, Patan is also acknowledged for providing laboratory facility during the research work.

\section{References}

Dharaiya N. (2001). A study on the ecology of satellitic lion metapopulation around Gir PA and its conservation. Ph.D. Thesis, Saurashtra University, Rajkot.

Dharaiya N. (2008): To find out occurrence, distribution and status of some rare and small mammals in the North Gujarat Region. Final Report Unpublished. Gujarat Forest Research Institute, Gandhinagar. 87 Pp.

Dharaiya N. \& Ratnayeke S. (2009): Escalating Human sloth bear conflicts in north Gujarat: a tough time to encourage support for bear conservation. International bear news, 18 (3): 12-14. 
Gajera N. \& Dharaiya N. (2011): Status, Occurrence, Distribution of some mammals of North Gujarat, India. Proc. Zool.Soc., $64(1): 46-53$.

Ikeda, N. (2004): Economic impacts of livestock depredation by snow leopard (Uncia uncial) in the Kanchenjunga Conservation Area, Nepal, Himalya. Environ. Conserv, 31 (4):322-330.

Linnell J.D.C., Swenson J.E. \& Andersen R. (2001): Predators and people: conservation of large carnivores is possible at high human densities if management policy is favorable. Anim. Conserv., 4:345-349

Madhusudan M.D. \& Mishra C. (2003): Why big, fierce animals are threatened: conserving large mammals in densely populated landscapes. In-M. Rangarajan and V. Saberwal eds.: Battles over nature: the science and politics of conservation in India. Permanent Black, New Delhi

Mishra C. (1997): Livestock depredation by large carnivores in the Indian trans-Himalaya: conflict perceptions and conservation prospects. Environ. Conserv., $24(4): 338-343$.

Namgail T., Bhatnagar Y.V. \& Fox J. (2006): Carnivore-Caused Livestock Mortality. In- Trans-Himalaya. Environmental Management, xx, 1-8.

Primm S.A. \& Clarke T. (1996): Making Sense of the Policy Process for Carnivore Conservation. Conserv. Biol, 10: 1036-1045.

Singh H.S. (2002).Natural Heritage of Gujarat. Gujarat Ecological Education Research (GEER) Foundation, Gandhinagar. 262 pp.impact of globally rising underwater sound levels on fish. Trends in Ecology $\mathcal{E}$ Evolution, 25: 419-427

Soares D. \& Niemiller M.L. (2013): Sensory adaptations of fishes to subterranean environments. Bioscience, 63: 274283.

Von Frisch K. (1938): The sense of hearing in fish. Nature, 141: 8-11. 